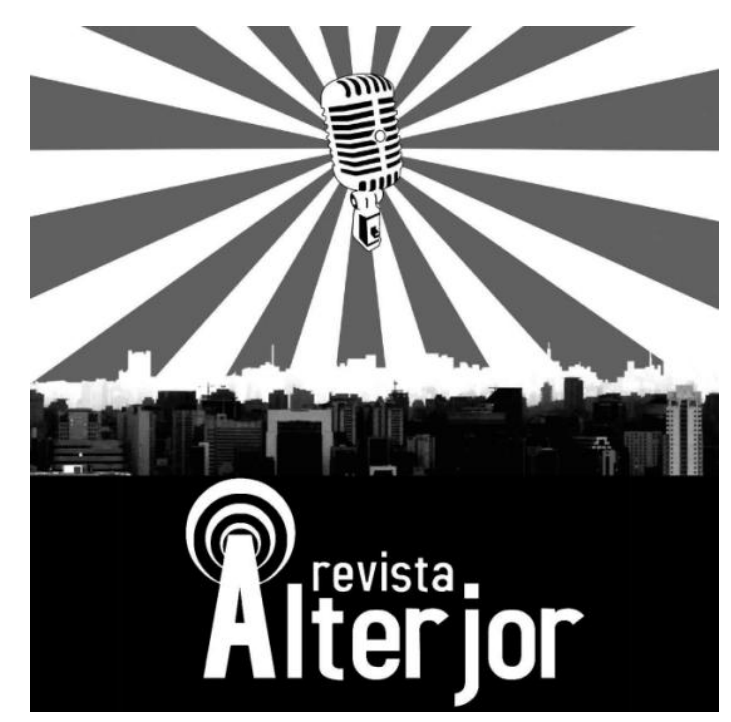

\title{
POR QUÊ A PRISÃO DE UMA JOVEM NEGRA É UM PROBLEMA PÚBLICO?
}

Lucas Afonso Sepulveda ${ }^{1}$

RESUMO: O artigo presente investiga o acontecimento da prisão da Bárbara Querino de Oliveira, conhecida como Babiy, que responde em cárcere ao crime de roubo de um automóvel, em São Paulo. A proposta desse artigo é refletir sobre a forma como familiares e amigos, através dos discursos e conteúdos produzidos pela página do Facebook "Todos por Babiy", articulam a prisão da jovem como um problema público e racial, estrutural e racista, que deve ser digno de atenção de todos e qualquer um.

PALAVRAS-CHAVE: Problema público. Público. Encarceramento. Racismo. Redes sociais.

ABSTRACT: The present article investigates the event of the arrest of Barbara Querino de Oliveira, known as Babiy, who responds in prison to the crime of car theft in São Paulo. The purpose of this article is to reflect on how family and friends, through the speeches and content produced by the Facebook page "Todos por Babiy", articulate the arrest of the girl as a public and racial, structural and racist problem, which should be worthy of everyone's attention.

KEYWORDS: Public problem. Public. Incarceration. Racism. Social networks..

\footnotetext{
1 Jornalista e doutorando no Programa de Pós Graduação em Comunicação Social da Universidade Federal de Minas Gerais. Email: afonsepuv@gmail.com
}

\author{
Revista ALTERJOR \\ Grupo de Estudos Alterjor: Jornalismo Popular e Alternativo (ECA-USP) \\ Ano 10 Volume Ol Edição 23 Janeiro-Julho de 202l \\ Avenida Professor Lúcio Martins Rodriǵues, 443, Cidade Universitária, São Paulo, CEP: 05508-020
}




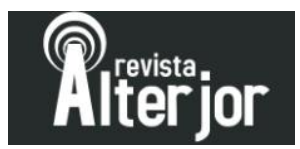

\section{INTRODUÇÃO}

Bárbara Querino de Oliveira, conhecida entre amigos e familiares como Babiy, é uma jovem negra, paulista, de 20 anos, réu em dois processos na Justiça brasileira. Ela foi apontada por vítimas de latrocínio como participante de dois roubos que aconteceram em 2017. Presa em 18 de janeiro de 2018, a jovem só conseguiu o direito de responder em liberdade em agosto de 2019 e foi plenamente inocentada em $2020^{2}$ isto é, ela passou um ano e cinco meses em prisão preventiva por um crime que não cometeu.

Em novembro de 2017, Babiy foi detida e fichada por agentes policiais, junto com uma amiga, pela primeira vez. Na delegacia, se juntaram a elas seu irmão, seu primo e dois outros jovens - todos suspeitos de serem os autores do assalto de um Audi A4. As jovens não foram reconhecidas pelas vítimas do assalto e foram logo liberadas não antes de passarem dezesseis horas presas dentro de um camburão e de serem fotografadas pelos policiais e filmadas pelo tabloide policial da TV Band "Brasil Urgente". Três dias depois do seu "fichamento" pela polícia, Bárbara foi prestar a prova do Enem, no intuito de entrar em uma universidade de jornalismo.

Nos dias e semanas seguintes, os retratos de Babiy e dos outros circularam em diferentes grupos do WhatsApp e Facebook. As imagens chegaram na mão de um delegado, que as enviou para um casal que teve uma Honda Civic levada durante um assalto. Os dois, por sua vez, confirmaram ao policial que aqueles eram os "cinco indivíduos pardos" " que os assaltaram. Babiy, segundo os dois, se encaixava "100\%" na descrição de uma mulher "de cor parda, cabelos longos encaracolados da cor preta, olhos escuros, magra, altura aproximada de 1,68m, aparentando ter a idade entre 18 a 20 anos". Quando fizeram o reconhecimento pessoal, no entanto, o casal expressou dúvidas, não sabiam se aqueles eram, de fato, os autores do crime. Mesmo em dúvida,

\footnotetext{
2 STABILE, Arthur. “Condenada sem provas, Bárbara Querino é absolvida pela segunda vez”. El País, 14 de maio de 2020. Disponível em: https://brasil.elpais.com/brasil/2020-05-14/condenada-sem-provasbarbara-querino-e-absolvida-pela-segunda-vez.html. Acesso em: 9 de outubro de 2020.

${ }^{3}$ SALVADORI, Fausto. "Bárbara Querino, a Babiy: como a Justiça condenou uma jovem negra sem provas". Ponte Jornalismo, 19 de setembro de 2018. Disponível em: https://ponte.org/barbara-querino-ababiy-como-a-justica-condenou-uma-jovem-negra-sem-provas/. Acesso em: 9 de outubro de 2020.
} 


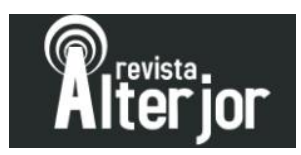

eles mantiveram a alegação de que Babiy seria uma das assaltantes porque o cabelo dela era "familiar" a da figura feminina que os assaltou. Babiy foi, então, indiciada.

As fotograafias tiradas de Babiy na delegacia também circularam nas redes por militares durante a identificação de suspeitos de um assalto de uma Honda CR-V. Na identificação pelas vítimas na delegacia, uma das vítimas do assalto do automóvel reconheceu a garota pelas mesmas características que o casal que teve o outro carro assaltado: cor "parda", cabelos cacheados, olhos escuros, pouca altura e jovem. Quando foi apresentado à foto de Babiy, o homem também a reconheceu, com "certeza", tanto diante do retrato, quanto no reconhecimento pessoal com a jovem. Como relata o site Ponte, na apuração do caso, esse segundo processo de identificação também foi feito com os mesmos problemas e irregularidades que o primeiro. Babiy foi indiciada em um segundo processo de roubo.

A jovem foi presa em janeiro de 2018. Sete meses depois, teve seu primeiro julgamento: apesar da defesa argumentar que Babiy não poderia ter assaltado o Honda CR-V por estar a 90km de distância do local do crime, trabalhando como modelo em Guarujá, com fotografias postadas em redes sociais dela na cidade e testemunhas, o juiz alegou que o argumento da acusação - a identificação das vítimas - era mais forte. Foi só e novembro de 2018, após pedido de habeas corpus, que a jovem foi inocentada da condenação feita em que ela apresentou álibi. Ela permaneceu encarcerada, no entanto, pelo segundo processo.

Três roubos de automóveis, e dois processos na justiça, dois reconhecimentos irregulares pelas vítimas - como o perito da defesa de Babiy alegou - causaram a prisão de Bárbara. Todos esses procedimentos legais aconteceram junto com uma atividade incessante da mãe, por atenção pública, e, em especial, de uma das amigas de Bárbara: Mayara Viera, de 23 anos, que criou a página de Facebook "Todos por Babiy". Vale dizer que a amizade entre as duas só surgiu depois da prisão de Babiy; Mayara criou o "movimento" depois que teve contato com a mãe da garota. Alguns meses após a prisão da jovem, a página em sua defesa alcançou milhares de seguidores e a história da modelo presa injustamente conseguiu chamar a atenção de diversos usuários e usuárias da rede e, consequentemente, de muitos canais da mídia militante, da mídia corporativa, 


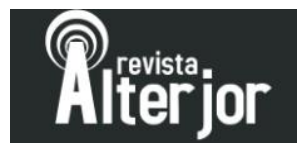

e de celebridades, como Lázaro Ramos, que a enviou uma cópia autografada de sua autobiografia, "Na minha pele".

"Todos por Babiy" publicou os mais diferentes tipos de conteúdo. Cotidianamente, informou sobre o estado da garota na prisão; relatou novidades nos tramites judiciais; mostrou momentos da vida da jovem que não estão relacionados ao acontecimento de sua prisão (seu trabalho como modelo e dançarina, a relação com seus familiares e amigos, os sonhos para o futuro); o relato de amigos e parentes de Babiy; desenhos e publicações feitas por "fãs" da garota e pessoas, que não a conheciam, mas estavam aliadas na sua defesa; notícias da imprensa; conteúdos sobre outros casos de prisões injustas e indevidas, de outras famílias que estavam (e ainda) estão passando pela mesma situação que a família de Bárbara: a perda de um parente inocente, a violência de um racismo estruturado nos órgãos de policiamento e de Justiça no Brasil.

A proposta desse texto, diante desse acontecimento e mobilização, é questionar: como a prisão de uma mulher negra pode se articular como problema público? Iremos observar as diferentes estratégias e os discursos empregados pela página "Todos por Babiy" para entender de que forma essa aparição de Bárbara Querino é convocada de forma estratégia e se articula, para mais que um problema de um, como um problema de muitas e muitos. A seguir, portanto, iremos apresentar alguns eixos teóricos convocados para essa análise: a articulação de um problema público e o apontamento das desigualdades raciais que estruturam a cena pública, em suas dimensões institucionais, legais e sociais.

\section{Articulando um problema público e racial}

O que é um problema público? Uma definição inicial é oferecida pelo pragmatista John Dewey. Ele traça uma distinção do não-público e do público, sendo o primeiro relativo às ações ou as transações entre partes que somente afetam essas partes envolvidas, ou, ao menos, cujas consequências estão limitadas às próprias partes; e o segundo, o público, relativo às ações ou transações que afetam indiretamente outras partes e são reconhecidas como possuindo consequências para muitos e, dessa forma, se torna um problema "[...] que precisa ser controlado, seja por inibição ou por promoção" 


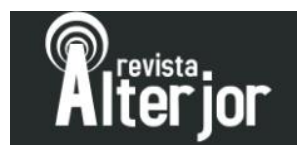

(DEWEY, 1946, p. 15, tradução nossa). O público, portanto, pode estar relacionado com as consequências indiretas que precisam ser controladas, supervisionadas ou debatidas.

Mas como se forma um problema público? Para que um acontecimento se torne um problema público, é preciso que ele seja articulado, pelas próprias pessoas afetadas, como algo que possui afetações indiretas e que deve ser, dessa forma, um problema tratado à vista e à escuta de todos ou qualquer um, isto é, em um cenário ou em uma plataforma pública. Articular um problema público, dessa forma, se revela como uma atividade em que alguém tenta mostrar a forma como muitos e muitas, e, de certa forma, todos e todas estão indiretamente implicados naquele acontecimento e naquele problema. Como Dewey escreve, a construção de um público é a consequência da associação entre sujeitos. Se o público diz sobre essas associações, consequências e afetações, devemos pensar na experiência de formação de um público como uma experiência de interdependência - dependemos uns dos outros não só para sobreviver, como nos lembra Dewey, mas para articular algo público - e intersubjetividade - o problema público se articula através da relação uns com os outros e é conformado pela interlocução, na negociação e confronto com o outro, dependendo de compreensão simbólica e discursiva.

A articulação de um problema público, portanto, também é a articulação de algo ainda não-reconhecido como problema ou a ser reconhecido como um. Isto é, um problema público se torna problema público ao afetar sujeitos e indivíduos indiretamente na constatação de que algo na ordem das coisas necessita de mudança, necessita de supervisão ou regulação, necessita ser discutido publicamente, oficialmente, estatalmente ou, pelo menos, por muitas e muitos. De fato, um público afetado e articulador de um problema, como aponta Babo-Lança, não preexiste ao acontecimento que o constitui. Ao contrário, ele só existe em relação à própria ação solidária e produtora de sentido diante do mundo que o faz; o público só "torna-se público através de uma experiência pública, em que se sente e publicita manifestações de apoio, de indignação, de justificação, de denúncia, de juízo estético, ético ou político, de crítica, etc. [...]" (BABO-LANÇA, 2007, p. 60). O público, portanto, enquanto se 


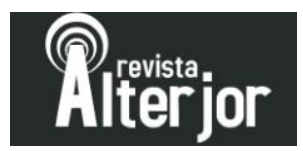

relaciona criticamente a determinada normatividade ou normalidade: algo acontece, esse público se afeta, se emociona, se associa e se articula, colocando algo que é dado como normal, natural, vigente, em cheque. Esta é a articulação de um problema público, que sempre será um problema político porque, "para se formar, o público precisa romper as formas políticas existentes” (DEWEY, 1946, p. 81). Não existe, portanto, a articulação de um problema público que não esteja relacionada ao tecido social, a um ethos vigente, como nos lembra Babo-Lança (2007), ou à normatividade e à ordem social, e, principalmente, às hierarquias de poder. Consequentemente, podemos considerar que diferentes grupos sociais em diferentes condições políticas possuem possibilidades e desafios também diferentes para articular um problema público, mobilizar interlocutores e acionar a atenção e estatuto do Estado para suas pautas. Dessa forma, como podemos pensar a constituição de um problema público que também é um problema racial?

Silvio Almeida (2019) nos lembra: antes de um fenômeno individual, ou lido somente em seu aspecto institucional, o racismo é um fenômeno estrutural. Isto é, ele é um fenômeno discriminatório que atravessa, diretamente e indiretamente, o cotidiano, as instituições públicas e privadas, o Estado e sociedade. O racismo opera ideologicamente, se instaurando como um fenômeno da normalidade, ao mesmo tempo que esconde as condições por qual opera. O que podemos concluir é que não existe uma neutralidade diante da sociedade racista e "[...] as instituições que não tratarem de maneira ativa e como um problema a desigualdade racial irão facilmente reproduzir as práticas racistas já tidas como 'normais' em toda sociedade” (ALMEIDA, 2019, p. 48). Concretamente, diante do racismo, não há como existir neutralidade; afirmar que não é um "problema meu” ou da minha instituição é participar da manutenção produtiva da estrutura racista.

Isso nos mostra outro aspecto da sociedade racial: estamos todos, brancos e nãobrancos, negros e não-negros, envolvidos como participantes da estrutura racista: brancos se beneficiando de posições exploradoras da hierarquia racial, negros sendo explorados ou violentados por serem negros. Se compreendemos que a "raça" e a categoria de ser "negro" não são construções biológicas, mas históricas, que datam da expropriação de africanos na escravidão moderna e, hoje, em uma sociedade 


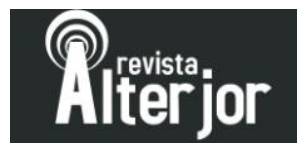

racialmente hierarquizada e exploradora, encontram novos contextos de apropriação e subversão (MBEMBE, 2018), entendemos que somos sujeitos sempre uns em relação aos outros, brancos e negros em relação a outros brancos e negros (KILOMBA, 2011) uma relação cuja premissa é a próprio vínculo de responsabilidade diante da estrutura.

Dessa forma, se pensarmos que estamos todos estamos embebidos e estamos sendo constituídos pela estrutura racial, percebemos que o racismo é um problema de todos e de qualquer um, porque a raça opera produzindo corpos em relação. Consequentemente, o racismo possui uma dimensão que é inevitavelmente pública ou se torna pública ao ser identificada, por mais que ele frequentemente seja ideologicamente escondido através das arenas privadas da vida, como o lar, o trabalho, a escola, as relações pessoais. Afinal, delimitar uma ação como algo da arena privada da vida é, nos termos de Dewey, apontar que aquilo ali possui consequências apenas para os indivíduos envolvidos na ação; consequentemente, não diz respeito aos outros, ou a outros atravessamentos que constituem a vida social, as estruturas sociais, ao Estado.

Definir algo um problema não-público é quase que afirmar: isso não é um problema de todos, de muitas e muitos, de qualquer um; é um problema de poucos e não devemos articular como um problema público. É encerrar o debate, é impedir a articulação de um público que exige interlocução diante de algo que é tomado como errado ou injusto, e que pode e deve ser transformado em outra coisa. Essa estratégia de silenciamento é tão comum ao racismo brasileiro, que não é difícil encontrar pesquisas que mostrem que o racismo nunca é jogado como um problema nosso, um problema branco e negro, um problema público. Como escreve Schwarcz (2012), enquanto a maioria concorda com a afirmação de que o racismo se manifesta na nossa sociedade, poucos são aqueles que afirmam terem reproduzido o racismo em suas relações.

Muitas das pautas sobre as violências vivenciadas pela população negra, dessa forma, encontram pouco espaço para debate e reflexão porque é grande a indisposição da população branca para discutir sobre o racismo, como um problema público, como um problema também branco. As estratégias para a recusa desse debate são das mais diferentes e são narrativas quase constituidoras da nossa cultura e sociedade: uns tentam explicar e "acalmar" os ânimos dos indignados dizendo que a desigualdade se justifica 


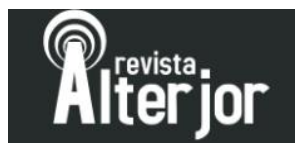

por sermos, negros e brancos, biologicamente diferentes - como se estruturas morais e sociais estivessem biologicamente localizadas e, portanto, impossibilitadas de serem acessadas ou alteradas; outros, como o presidente Jair Bolsonaro, alegam que não há mais possibilidade de haver racismo em nosso país ${ }^{4}$, sendo essa questão algo de um passado muito distante e que deve ser esquecido - vivemos, pois, numa "democracia racial", miscigenados demais em uma mesma cultura para sermos tão diferentes ${ }^{5}$. O que discursos biologizantes ou atomizantes do conflito racial escondem é a própria realidade da estrutura racista. Não é preciso apresentar dados extensos; alguns dados sobre mortalidade - quem é deixado à morte no país? - renda e educação - quem tem menos acesso ao saber oficial e ao capital? - e punição - quem são os declarados inimigos da sociedade? - já revelam um cenário de extrema desigualdade racial.

Outro sintoma da operação estrutural do racismo se revela no nosso sistema judiciário e penal: pessoas negras são mais punidas pelo Estado que pessoas brancas. A principal tipificação das sentenças de pessoas negras é o tráfico de drogas e associação com o tráfico. Desde a Lei $N^{o} 11.343 / 2006$, que legisla sobre a apreensão de drogas e não define parâmetros para a distinção entre "traficantes" e "usuários", o número de presos por crimes relacionados ao tráfico aumentou drasticamente. Como Juliana Borges (2009) aponta, o número de presos entre 1990 e 2005 era de 27 mil homens e mulheres em cárcere; depois, entre 2006 a 2014, a população carcerária cresceu para 200 mil pessoas. Como explicar esse crescimento? Uma possibilidade é o fato de que a política de drogas tornou mais fácil punir qualquer indivíduo pego pela polícia com alguma quantidade de droga, sendo a diferenciação entre um "traficante" e um "usuário" exclusivamente deixada à decisão ideologicamente fundada dos policiais militares que fazem a apreensão aos juízes que decidem a pena para o apreendido.

A consequência de uma política "antidrogas" é que deixa a definição de quem qualifica como usuário ou traficante para parâmetros subjetivos, racistas e frequentemente violentos. Vemos aqui um exemplo para outras apreensões e

\footnotetext{
${ }^{4}$ RAMOS, Gabriela. "Aqui no Brasil não existe isso de racismo, diz Bolsonaro em Fortaleza". Estadão, 28 de junho de 2018. Disponível em: https://politica.estadao.com.br/noticias/eleicoes,aqui-no-brasil-naoexiste-isso-de-racismo-diz-bolsonaro-em-fortaleza,70002375442. Acesso em: 9 de outubro de 2020.

${ }^{5}$ Cf. NASCIMENTO, 1978.
} 


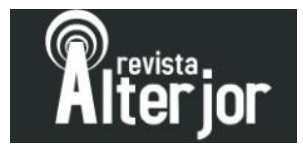

tipificações de pessoas negras e, principalmente, mulheres negras: elas estão em condições mais precárias que os brancos, estão mais perseguidas pela legislação que os brancos, estão frequentemente sendo mais detidas e de forma abusiva que os brancos, correm mais risco que os brancos de serem detidas, punidas e presas (BORGES, 2019). O Brasil tem 42.355 mulheres vivendo no sistema penitenciário ou nas carceragens de delegacias, segundo dados de 2016 do IBGE, e possui a terceira maior proporção de mulheres presas a cada 100 mil habitantes: são 40,7, atrás da Tailândia, com 60,7 para 100 mil habitantes, e Estados Unidos, com 65,7 para a mesma proporção. No entanto, nenhum desses países teve um crescimento tão grande da população carcerária feminina nas últimas décadas como o Brasil.

Bárbara Querino é uma das milhares que entraram nessas categorizações da população carcerária: é uma jovem negra que respondeu a um dos seus processos criminais em regime fechado; possui ensino fundamental completo, mas teve os planos de tentar um ensino superior interrompidos pela prisão; seu primeiro sentenciamento previa cinco anos de cadeia, equiparando-se à média de anos que a maioria das mulheres em cárcere recebem como pena. Por seu irmão ter confessado a participação em roubos, ela também acabou sendo mais facilmente "associada" à atividade criminosa pelas autoridades. Vale também apontar a irregularidade da apreensão da garota: todo o processo de identificação foi feito de forma, ao menos, desleixada, considerando que as imagens de Babiy foram "vazadas" para grupos de WhatsApp e para a imprensa, e usadas para promover as identificações racistas das vítimas, baseadas apenas em fisionomias comuns de mulheres negras, sendo pouco indicativas, de fato. Esse foi, inclusive, o argumento do perito contratado pela defesa da garota.

Ao tratarmos da articulação de um problema público, apontamos para um pano de fundo cultural e político (BABO-LANÇA, 2007), que ordena as coisas de forma a criar algo vigente e com a aparência de "natural". Aponta-se aqui, dessa forma, que algo que é de todos, isto é, que é público, está errado ou agindo de forma destrutiva, e que essa destruição e cerceamento do corpo negro afeta não apenas a um ou dois, mas à sociedade como um todo, produzindo um sistema de injustiças seletivas. O caso de Babiy levanta um problema não somente com sua prisão injusta, e inquérito 


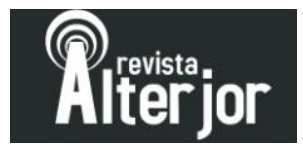

irregularmente construído, mas também contra a seletividade penal do sistema de Justiça brasileiro, a apreensão violenta dos agentes militares em favelas, e do racismo que deseja finalizar a humanidade das pessoas negras na alcunha do "criminoso", entre outros termos que tentam justificar a perseguição e o encarceramento em massa dessa população (BORGES, 2019).

A prisão da garota dessa forma é apresentada por sua família, amigos e outros sujeitos envolvidos na luta pela sua liberdade como o sintoma de muitos problemas públicos, que atingem desde um espaço e tempo mais reduzido, ao consideramos a próprio caso da prisão da garota, até um espaço e tempo longo e ampliado, por possibilitar uma reflexão maior sobre como se deu, como se dá, e como se darão as outras prisões injustas da população negra e favelada no país. A seguir, portanto, olharemos para algumas das estratégias articuladas pela família e envolvidos na página de Facebook "Todos por Babiy" - a principal interface de comunicação e articulação com o público. Propomos aqui menos uma reflexão sobre as "melhores" ou "piores" formas de articular um problema público discursivamente, e mais uma reflexão sobre como se é articulado nesse acontecimento um diálogo com sentidos, valores, relações e estruturas.

\section{2. “Todos por Babiy": quando uma mulher negra aciona o público}

A página "Todos por Babiy" foi criada em 1 de fevereiro de 2018, cerca de duas semanas após a prisão de Bárbara Querino, por Mayara Vieira, assistente social de 23 anos, moradora do mesmo bairro que a jovem encarcerada. Elas se tornaram amigas após a prisão de Bárbara, se conhecendo fora da penitenciária pela primeira vez na primeira saída de Babiy durante o feriado de Páscoa, em 2019. Sobre o engajamento de Vieira, Babiy relata que "[...] Deus me enviou um anjo chamada Mayara Vieira que tem o coração enorme e vejo em seus olhos a vontade de abraçar o mundo".

A página do Facebook agregava, até a redação desse trabalho, cerca de 22 mil seguidores - e no Instagram - que, agora, recebe seu nome e autoria em vez de "Todos por Babiy" - 25 mil. Para observarmos como se dá a articulação de um problema público, isto é, de um problema que diz respeito indiretamente a muitas e muitos, 


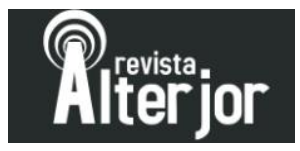

iremos observar os registros e publicações das duas páginas desde a primeira saída da prisão de Bárbara Querino, em 18 de abril de 2019, até o momento da redação deste trabalho. Temos, portanto, no Instagram, 33 postagens até o dia 10 de junho de 2019; e no Facebook, 38 publicações - muitas delas, no entanto, são semelhantes para as duas plataformas.

Queremos, aqui, menos "produzir" um conhecimento sobre essas produções discursivas do "Todos por Babiy", e mais apresentar ao território acadêmico o saber produzido pela página (e sua administradora) sobre a articulação de um problema público nas redes sociais digitais, através da prisão injusta da jovem dançarina. Das diferentes estratégias e táticas de articulação de um problema público, descrevemos aqui as três que, ao nosso ver, parecem as mais frequentes ou específicas da página em questão: uma articulação por legitimidade, por solidariedade e pelo reconhecimento de uma vida interrompida.

\subsection{A articulação por legitimidade: a imprensa e a militância}

Nesse período analisado, encontramos a articulação do movimento "Todos por Babiy" na primeira saída da dançarina para que houvessem entrevistas com a imprensa - os sites Brasil de Fato e Ponte.org tiveram principal acesso e gravaram com a garota em liberdade temporária, gerando reportagens mais longas sobre sua chegada em casa pra a Páscoa. Ambos os portais adotaram um enquadramento semelhante ao lidarem com o acontecimento: o primeiro endereça que, na manchete, que Babiy foi "presa injustamente"; o segundo, traz um trecho da entrevista com Babiy para o título: "sou a prova viva de que o Brasil é racista”. Também há a aparição do caso no site de jornalismo sobre questões raciais "Alma Preta", no portal de notícias e de entretenimento da Bahia, Aratu On, e há a divulgação da série do canal AXN, "Questão de Justiça", programa comandando pela criminóloga Ilana Casoy sobre decisões judiciais brasileiras postas em questão pelo público ou por especialistas.

Se a articulação de um problema público envolve os sistemas culturais vigentes e o domínio do que é legível culturalmente como um problema, a autoridade que a imprensa e a militância agregam ao dizer sobre a prisão de Bárbara Querino deve ser 


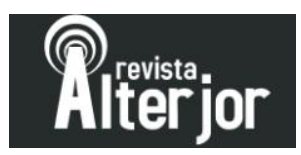

levada em conta. Essa negociação é, por sua vez, feita nas diferentes condições possíveis, e geralmente altera-se e perde-se algo nessas reapropriações e criações narrativas do acontecimento pelos diferentes canais de mídia. Sobre as dificuldades de articulação com esses meios, Viera, a principal administradora da página, escreveu, na sessão fixada de "dúvidas" do Instagram: "Eu e Babiy sempre conversamos por carta a respeito da militância por conveniência. Mas é aquilo né? Aproveitam de lado, mas aqui também precisamos ser estratégicas para o mesmo". De fato, parece haver a necessidade de que, para que o caso receba ainda mais atenção pública e mobilize pessoas, gerando mais pressão social sobre o aparato estatal e jurídico, é necessário que se utilize da mídia e permita-se gravar, falar, publicar - mesmo que algo seja perdido no processo.

\subsection{A articulação por solidariedade: a luta conjunta com outras prisões racistas}

Nesse curto período analisado, encontramos também a menção das páginas do "Todos por Babiy" de outros casos semelhantes de prisões injustas. Um caso de bastante diálogo com a página é o de Igor Barcelos, um jovem de 21 anos, negro, condenado a 15 anos e seis meses, na acusação de ter sido o autor de uma tentativa de latrocínio contra um policial militar em Guarulhos. A família protesta contra a condenação, já que, no horário em que o crime ocorreu, o rapaz estava no hospital: Igor estava andando de moto com amigos, saindo de uma festa, quando foi ele mesmo vítima de uma tentativa de latrocínio, sendo atingindo por uma bala na perna. No hospital, o jovem foi fotografado por militares e "reconhecido" por outro militar que havia sofrido uma tentativa de latrocínio. O que não bate, no entanto, é o tempo: o crime por qual Igor respondeu na justiça teria acontecido às 5h40, enquanto o jovem deu entrada no hospital às $5 \mathrm{~h} 44$, estando a 12,2 km de distância do local do crime.

A família de Igor participou presencialmente em uma das manifestações na rua que foram feitas por Babiy, com relata a página. Ao divulgar, no dia 8 de maio, a arrecadação feita pela família de Igor para a viagem da sua mãe no Dia das Mães para o presídio do filho, a página "Todos por Babiy" escreveu: "Dona Elisabeth é mais uma mãe preta vítima do sistema genocida e encarcerador brasileiro" que "teve seu filho 


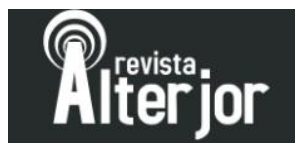

preso injustamente, por um crime que não cometeu, com provas concretas ignoradas pelo Estados. Provar a inocência de um jovem negro da periferia não é tarefa fácil [...]”.

Em outras datas, a página também divulgou publicações que pediam arrecadação para a mãe de Igor, que sofria com o desemprego e pela impossibilidade de visitar seu filho na prisão. A página também divulgou, no dia 4 de maio, que o programa dominical da TV Globo, o "Fantástico", iria exibir uma reportagem sobre o reconhecimento de suspeitos em investigações criminais, e falar sobre o caso de Igor. Após a exibição da matéria, a página de Babiy escreveu, com tristeza e indignação, sobre os comentários negativos acerca do caso do jovem, "sem nenhum respeito ao Igor e principalmente aos familiares que estão nesta luta para prova sua inocência há mais de dois anos".

Outra articulação da página é com Marcelo Dias, cuja família, junto da de Igor e da de Babiy, se articularam, presencialmente e virtualmente, em protesto contra suas prisões injustas. "Dentre nós, infelizmente sou o único que consegui minha liberdade. Mas minha luta não para, continuarei orando incansavelmente e lutando para ver Babiy e Igor o mais breve na Rua", escreve Marcelo, no dia 28 de abril, em um post compartilhado pelo "Todos por Babiy". O educador de 39 anos, líder comunitário gay, presidente da ONG "Novos Herdeiros" e membro de uma organização filiada à ONU, foi preso em flagrante após ver, em seu carro, uma sacola sendo deixada na rua de forma suspeita por dois homens, e acionar policiais; os militares voltaram com a sacola, que continha $5 \mathrm{~kg}$ de pasta base, e acusaram Marcelo de ser membro de uma quadrilha do tráfico de drogas. O homem passou seis meses preso, respondendo em regime fechado sem que houvesse provas concretas para sua acusação que não o testemunho dos policiais. Recebeu habeas corpus em dezembro de 2018 e foi absolvido em abril de 2019.

Outros dois apontamentos também foram feitos na página durante o período analisado. Em 3 de junho, "Todos por Babiy" divulga, no Facebook, uma notícia da Ponte.org sobre a juíza de São Paulo que havia impedido o portal de realizar entrevista com dois irmãos presos, Victor e Tiago Terkeli, reconhecidos "pelos olhos" por vítimas de roubo. "Tempos atrás compartilhamos esse caso e sobre um ato que ocorreu na cidade dos meninos", escreve a página. "Infelizmente a justiça continua da mesma 


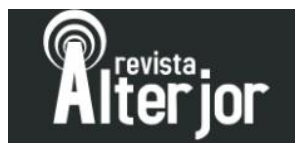

forma que ocorre com Babiy Querino, tendo a justiça censurado entrevistas com os reclusos”. Em 21 de junho, a página do Instagram publicou que se fazia seis anos da prisão do jovem negro Rafael Braga, o único preso durante das manifestações que aconteceram no Brasil em junho de 2013, por ter sido apreendido pela polícia com um desinfetante na mochila. O caso é emblemático exatamente por mostrar o sintoma da seletividade penal de uma estrutura racista.

Ao que nos parece, o mais interessante sobre essa articulação de solidariedade é que ela prova a dimensão pública desse e de outros acontecimentos: não se trata apenas de Babiy articulando sua luta contra o sistema judiciário, mas muitos e muitas famílias e conjuntos diretamente afetados articulando um problema contra a Justiça e o Estado, e convocando a ação de outros sujeitos diante de uma problemática racista e penal. É na articulação da solidariedade estratégica com outras prisões que também, ao que nos parece, se articula uma crítica profunda às hierarquias raciais de poder e à estrutura do racismo, sintomática, principalmente, no sistema judiciário. O "problema" de Babiy é, dessa forma, colocado também como um problema de muitos, vivido por muitos; um problema coletivo; e um problema social e político, isto é um problema que deve ser gerido socialmente, já que diz respeito a um bem público: a Justiça e seus defeitos, seus racismos.

\subsection{A articulação por reconhecimento de uma vida (interrompida, mas que} continua)

A taxação pejorativa de "criminoso" ou "bandido", que cria um inimigo social, reduzindo ou removendo sua humanidade e justificando sua eliminação, é frequentemente acionada contra a população negra brasileira (BORGES, 2019). Em uma dimensão simbólica, "Todos por Babiy” também luta contra essa categorização que a interpela e encerra sua vida ao nomeá-la como "criminosa". A luta da família, dos amigos e dos afetados e envolvidos por sua aparição pública, é uma luta contra o enquadramento que encerra a vida da dançarina e que impede de enxergarmos que ali havia uma vida que foi interrompida por uma prisão injusta e que, mesmo em cárcere, continua a ser vivida. A articulação desse problema público parece, portanto, também 


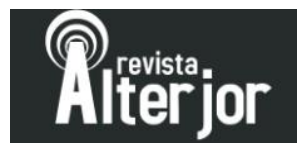

acontecer com uma proposição discursiva de reconhecimento. É desejado que as pessoas conheçam parte da vida privada de Bárbara e, dessa forma, se expõe, diversas vezes, fotografias, relatos, cartas e a voz da garota: muitos desses relatos, inclusive, são de alegria e força, já que se torna mais difícil remover a humanidade de algo que fala, luta, se articula e, mesmo em condições injustas e precárias, ainda manifesta vontade de viver.

Vale apontar que a primeira saída de Babiy foi divulgada em peso nas redes sociais, pelas páginas tanto do Facebook quanto Instagram. O desejo de Vieira, administradora da página, ao que nos parece, como espectadores, era transmitir ao máximo da teia de emoções, dos afetos e, de certa forma, do desejo da vida da família de Bárbara Querino, ao receber a garota em casa. "Dona Fernanda (mãe) exalando felicidade ao lado de Babiy", escreve a legenda de uma foto da mãe e filha, abraçadas, em casa, adicionando: “duas guerreiras”. Um ao vivo foi feito na página do Facebook, em que Babiy pôde conversar com internautas e responder perguntas, enquanto, no Instagram, pudemos assistir às diversas atividades que Querino, Vieira e amigas fizeram durante o fim de semana com a presença da dançarina.

A presença da voz de Babiy, mesmo que em poucos momentos, também é decisiva para a página, já que faz parte da experiência do cárcere ser privado ou limitado na sua exposição pública. Em entrevista ao Brasil de Fato, em sua primeira saída da prisão, na Páscoa, Babiy discorre criticamente sobre seu julgamento e prisão: "Como que uma vítima olha para mim e fala que me reconheceu por conta do meu cabelo? [...] eles não olham se você tem ensino médio completo, se você já trabalhou, se você tem carteira registrada, eles não olham isso. Olham sempre a sua cor. [...]". Durante sua fala, são exibidas as cenas de reencontro e conforto com família e amigos. Uma celebração de aniversário é feita na casa da mãe de Babiy, já que a dançarina passou a data em cárcere. Em outro momento, a jovem dá um relato sobre sua vivência nos meses de prisão e sobre a situação semelhante a sua, de mulheres que conheceu lá dentro:

Em Franco da Rocha, conheci muitas pessoas, muitas pessoas que são inocentes também, mas que não tiveram o mesmo apoio e as mesmas pessoas que eu tive nesse momento pra me ajudar. Pessoas que também por estarem no lugar errado, na hora errada, foram presas. Às 


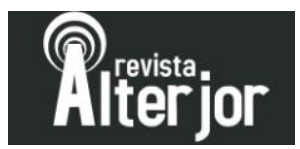

vezes, não tem prova, mas sabem que são inocentes, a família sabe que é inocente. Não tem tanto recurso para poder provar que você é inocente. Eu sei que eu estou presa, mas eu me correspondo com as meninas, eu sei que estou presa, mas eu tenho pessoas comigo. E quem não tem ninguém?

No dia 11 de maio, após a segunda saída de Babiy, brevemente, para o Dia das Mães, uma carta escrita pela garota foi publicada no Facebook:

Há 1 ano e 4 meses encarceirada, sentenciada 5 anos e 4 meses, não pude me expressar da maneira que queria. [...] Fui visitada diversas vezes por diversas pessoas, que sem ao menos me conhecer tiraram pelo menos 5 minutos para me escrever e me mostraram que nesta luta nunca estive só. [...] Através de vocês eu senti que doa a quem doer, eu tenho que falar. Não por mim, mas por centenas de jovens que diariamente sofrem alguma injustiça e não tem a quem recorrer. [...] Agora é a hora de surgir como uma Fênix que renasce das cinzas e mostrar para o mundo que não vou parar e devemos FALAR.

A exposição pública da voz que reflete sobre sua própria experiência e a exposição da vida privada - seja anterior à prisão, na prisão, ou nos momentos em que Babiy esteve fora da prisão - nos levam à uma dimensão crítica e ética da situação em que a jovem se encontra. Crítica, porque nos ajuda a refletir sobre os instrumentos de opressão e injustiça que atravessam uma vida ou, como vemos no caso, várias vidas; ética, porque nos proporciona um deslocamento de nossas vidas em direção à narrativa da garota, tornando difícil não reconhecemos aqui ali há devidamente uma identificação sobre o desejo de uma vida persistir e a reivindicação que ela persista, afinal, reconhecida como uma vida vivida - aspecto que a normatividade racista tenta suprimir da cena pública, ao oferecer, nos termos de Mbembe, uma humanidade "sustada" aos sujeitos e sujeitas negros.

Babiy, mesmo presa, fala e é falada por - na voz da página “Todos por Babiy". Ela dá um relato de si mesma, diante da interpelação e da violência que lhe foi imposta, nos termos de Butler (2017); ela responde à categoria de "criminosa", mostrando que, antes de um "detrito" vivo, ela é uma vida viva, e que fala - potencialidade inegável de quem é humano e vivo (COULDRY, 2010). Dessa forma, o que pode parecer apenas uma "celebração" não tão importante da vida privada, dos afetos, e da história de uma 


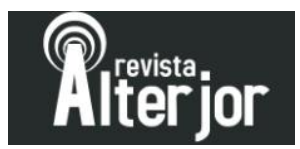

jovem operam, inevitavelmente, de uma forma política, ao levar o interlocutor diante dimensões inesperadas de uma vida interrompida pela prisão.

\section{Considerações finais}

Teorizar sobre um movimento social pode parecer, para o leitor desatento, uma prova de que é preciso muito saber e conhecimento para se lutar contra uma injustiça sistêmica. Essa constatação é apenas parcialmente verdadeira, e deve ser questionada, diante do caso que vemos: não é preciso estar dentro do espaço acadêmico, ou possuir o domínio legitimado de seus saberes científicos para que se possa refletir e encontrar estratégias para transformar e delimitar um acontecimento complexo em um problema público e político e agir, de forma estratégica, diante das estruturas.

As articulações que mencionamos aqui, por sua vez, parecem estar diretamente associadas com a leitura do social e do público. 1) Na tentativa de acionar um problema público, tenta-se convocar a legitimidade e autoridade de instituições de visibilidade pública, como a mídia. 2) Tenta-se encontrar aqueles que estão passando pela mesma situação que um passa, que vivenciam a mesma experiência como uma experiência problemática, e que articulam essa experiência publicamente, como um faz. 3) Diante da violência daqueles que ferem um indivíduo com uma categoria que encerra e desumaniza, tenta-se reivindicar o estatuto de humano e questionar as próprias condições políticas em que se distribui a humanidade para uns e para outros.

Esses recursos, ao que nos parece, são só alguns dos que são possíveis para aqueles que tentam mobilizar o tecido social em relação a uma pauta, a uma causa, ou a um acontecimento. Eles nos mostram alguns dos aspectos enunciados por Dewey (1946) na articulação de um problema público: trata-se de um processo intersubjetivo e interativo, que depende da própria articulação do que é visto ou não como um problema pelos outros a quem falo e, consequentemente, que desafia as formas políticas convencionais e hegemônicas. Pensar no caso Babiy e na página online de sua luta também nos abre para outra discussão: quais articulações sofridas por aqueles que tentam mobilizar um problema público quando esse problema público também é racial? O investimento em análises sobre essas articulações que denunciam a estrutura racista 


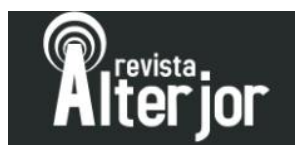

pode revelar problemas frequentes e repetitivos para aqueles que lutam contra a discriminação e injustiça racial, ao se porem no espaço público.

No entanto, de todas as características apontadas aqui, há de ressaltar a potencialidade que se dá através da solidariedade e potencialidade crítica: a articulação, por exemplo, das famílias e histórias de Babiy, Igor e Marcelo não são somente estratégicas para os seus "problemas" públicos, mas atuam exatamente em uma dimensão que ultrapassa suas histórias ao denunciar uma situação e vivência que muitos e muitas passam no Brasil. O problema público e singular dos três se revela, portanto, um problema estrutural no país. E mais que isso, a prisão de Babiy e sua denúncia de injustiça, pode ser o recurso para uma reflexão ainda maior sobre a historicidade do sistema penal e carcerário e seu compromisso de manutenção do racismo e aprisionamento. Babiy, em sua aparição, se torna, um signo político pela luta da "liberdade" - mais do que para ela, para seus novos articuladores, ela se torna esse signo para uma população politicamente presa e um signo para uma luta muito maior e ampla contra o sistema penal.

\section{REFERÊNCIAS}

ALMEIDA, Silvio. Racismo estrutural. São Paulo: Pólen, 2019.

BABO-LANÇA, Isabel. Problema Público Processos de Enquadramento: o caso Madeleine McCann. Trajectos, Revista de Comunicação, Cultura e Educação, Lisboa, n. 11, p. 47-66, 2007.

BORGES, Juliana. Encarceramento em massa. São Paulo: Pólen, 2019.

COULDRY, Nick. Why voice matters? Culture and politics after neoliberalism. London: SAGE Publications, 2010.

DEWEY, John. The public and its problems: an essay in political inquiry. Chicago: Gateway Books, 1946.

KILOMBA, Grada. A máscara. In: Plantation memories: episodes of everyday racism. Munster: Unrast Verlag, 2010.

MBEMBE, Achille. Crítica da razão negra. São Paulo: n-1 edições, 2018.

NASCIMENTO, Abdias do. O genocídio do negro brasileiro: processo de um racismo mascarado. Rio de Janeiro: Paz e Terra, 1978. 